\title{
PEMAHAMAN MATERI HAID UNTUK MENGETAHUI CARA MENGQODHO'SHOLAT WAJIB PADA SISWA SMP RADEN RAHMAT KARANGREJO WONOKROMO SURABAYA
}

\author{
Understanding of Haid Materials to Know How to Qodho' Sholat Required on \\ Students of Rahmat Karangrejo Raden Middle School Wonokromo Surabaya \\ Siti Maimunah, Elly Dwi Masita \\ Universitas Nahdlatul Ulama Surabaya \\ maimunah@unusa.ac.id
}

\begin{abstract}
ABSTRAK
Tujuan penelitian ini untuk mendeskripsikan: pemahaman materi haid dan istikhadhah terhadap cara mengqadho' solat wajib pada siswa SMP Raden Rahmat Surabaya.

Bentuk penelitian ini adalah deskriptif menggunakan pendekatan kualitatif. Subyek dalam penelitian ini siswa SMP Raden Rahmat Wonokromo Surabaya dan guru yang memegang materi haid dan istikhadhah, Pengumpulan data dilakukan dengan menggunakan metode observasi, wawancara, dan dokumentasi. Instrumen utama dalam melakukan penelitian yang dibantu oleh pedoman observasi, pedoman wawancara, dan pedoman dokumentasi. Teknik yang digunakan dalam analisis data adalah display data, reduksi data, dan pengambilan kesimpulan. Trianggulasi dilakukan untuk menjelaskan keabsahan data dengan menggunakan berbagai sumber.

Bersumber dari data yang telah dilaksanakan pada siswi SMP Kelas VIII bahwa pemahaman siswi SMP Kelas VIII pada materi haid dan istihadhah dalam mengqadhok solat wajib, hasilnya baik. Perolehan ini dapat dilihat dari data nilai materi haid dan istikhadhah dan data dari hasil wawancara yang telah disampaikan kepada siswa SMP Raden Rahmat Surabaya, Materi haid dan istikhadhah yang telah diajarkan kepada siswa SMP Kelas VIII sudah mereka fahami sehingga siswa dapat mengetahui cara mengqadho' solat wajib walaupun masih ada sebagian materi yang masih kurang dimengerti, seperti cara membedakan darah wanita termasuk darah haid atau darah istikhadhah.
\end{abstract}

Kata kunci: Materi haid dan Istikhadhah, qodho' solat wajib

\section{ABSTRACT}

This study aims to describe: to know the understanding of menstrual material to find out how to qadho 'obligatory pr The purpose of this study is to describe: understanding menstrual material and how to practice the way to qadho 'obligatory prayers for students of Raden Rahmat Middle School in Surabaya.

The form of this research is descriptive using a qualitative approach. The subjects in this study were Raden Rahmat Wonokromo Surabaya Middle School students and teachers who held menstrual material and istikhadhah, Data collection was done using the method of observation, interviews, and documentation. The main instrument in conducting research is assisted by observation guidelines, interview guidelines, and documentation guidelines. The technique used in data analysis is displaying data, reducing data, and drawing conclusions. Triangulation is done to explain the validity of data using various sources.

Based on the data that has been carried out on Grade VIII Middle School students that the understanding of Class VIII Middle School students on menstrual material and istihadhah in compulsory prayer is compulsory, the results are good. This acquisition can be seen from the data value of menstrual material and istikhadhah and data from the interview results that have been delivered to Raden Rahmat Middle School students in Surabaya. The menstrual material and teachings that have been taught to Middle School students of Class VIII are understood so students can know how to practice compulsory prayer although there is still some material that is still poorly understood, such as how to distinguish a woman's blood including menstrual blood or istikhadhah blood.

Keywords: Menstrual material,qodho'compulsory prayer 


\section{PENDAHULUAN}

Usia wanita ketika masuk di bangku SMP kebiasaannya sudah mengalami haid, kebanyakan siswa masih belum mengetahui dan memahami materi tentang hukum darah haid. Siswa belum memahami dan cara membedakan apa yang dinamakan darah haid dan yang disebut darah istikhadhah, karena siklus haidnya yang tidak teratur, sehingga siswa masih banyak yang belum memahami cara mengqodho' solat wajib.

Materi haid dan istikhadhah merupakan materi yang sangat penting karena ada hubungannya dengan cara mengqadho' solat wajib terutama terhadap siswa SMP Kelas VIII Raden Rahmat Wonokromo Surabaya. Sehingga pembelajaran materi tersebut dilaksanakan setiap hari kamis dan buku yang dipakai acuan dalam pembelajaran tersebut adalah buku paket yang dari DEPAG dan ditambah buku risalatul makhid.

Wanita yang mengalami haid merupakan suatu kebiasaan yang terjadi pada seorang perempuan yang normal dan sehat setiap bulan akan mengalaminya ketika sudah mencapai usia baligh. Jika, sebaliknya apabila waktunya itu haid mundur, hal itu akan menjadikan adanya persoalan, baik bagi perempuan yang sudah menikah maupun yang tidak belum menikah, yaitu dikhawatirkan adanya penyakit atau sebagai tanda kehamilan.(Huzaemah Tahido Yanggo, 2010)

Para ulama bersepakat bahwa minimal umur wanita yang mengalami haid adalah 9 tahun. Apabila darah yang keluar sebelum umur tersebut maka darah itu tidak termasuk sebagai darah haid akan tetapi darah istikhadhah atau darah penyakit. Batasan minimal dan maksimal keluarnya darah haid tidak bias ditentukan dengan pasti, karena dasar-dasar yang dijadikan sebagai landasan penentuan batasan minimal dan maksimal haid sebagaian berstatus mauquf sehingga tidak dapat dijadikan dalil, dan berstatus marfu', akan tetapi tidak benar. Sehingga dasar tersebut tidak bisa dijadikan sebagai pegangan dalam menentukan batas minimal dan maksimaluntuk menentukan keluarnya darah haid. Namun, yang dipakai acuan dalam hal ini adalah kebiasaan yang berulang-ulang, hal ini bagi wanita yang mempunyai siklus haid yang teratur, sedangkan bagi yang siklus haidnya tidak teratur maka ia dapat berlandasan pada hitungan siklus haidnya. (Abdul Aziz Muhammad Azzam dan Abdul Wahhab Sayyed Hawwas, 2009).

Darah yang keluar sesudah batas maksimal darah haid dianggap darah istihadhah atau sering disebut sebagai darah penyakit (darah penyakit). Hal itu untuk membedakan darah haid dan darah istihadhah biasanya dapat diketahui melalui warna dan baunya darah. (Syaikh al'Allamah Muhammad bin 'Abdurrahman ad-Dimasyqi, 2013)

Penjelasan ini dapat dijadikan pegangan untuk mengetahui waktu keluarnya darah haid juga untuk mengetahui terhentinya darah haid, oleh karena itu, shalat harus ditinggalkan. hukum yang telah ditetapkan oleh Allah SWT bagi seorang yang sedang memiliki hadas besar agar tidak melaksanakan shalat hingga dirinya mandi. Hal ini menunjukkan bahwa tidak ada masa suci bagi orang yang punya hadas besar kecuali setelah ia mandi dan tidak ada masa bagi perempuan yang sedang haid kecuali telah berhenti haidnya kemudian mandi. (Asmaji Muchtar, Fatwa-Fatwa Imam Asy-Syafi'i. 2013)

Responden dalam penelitian ini adalah siswa SMP kelas VIII karena mereka waktunya mengalami masa haid dan bertepatan materi haid diberikan kepada siswa SMP Kelas VIII. Agar siswa dapat mengaplikasikan materi haid dan istikhadhah dalam menjalankan ibadahnya sehari-hari terutama dalam menjalankan ibadah solat, karena kewajiban 
mengerjakan ibadah solat sangat erat hubungannya dengan masalah haid.

Alasan penulis memilih SMP Raden Rahmat Wonokromo Surabaya sebagi tempat penelitian karena ada beberapa pertimbangan diantaranya karena SMP ini menjadikan buku panduan agama Islam dan kitab risalatul Mahid yang didalamnya menerangkan tentang materi haid dan istihadhah sebagai satu kesatuan mata pelajaran yang harus disampaikan kepada siswanya. Akan tetapi tidak semua siswa memahami mengenai materi darah haid dan darah istihahadhah, padahal hukum belajar tentang materi haid dan istikhadhah bagi perempuan yang sudah masuk usia baligh adalah wajib (fardhu ain). Dengan demikian, penulis ingn mengetahui lebih dalam tentang memahaman siswa terhadap materi haid dan istihadhah.

Berdasarkan pembahasan diatas, maka peneliti membuat tulisan dengan judul "Pemahaman Materi Haid Untuk Mengetahui Cara Mengqodho' Sholat Wajib Pada Siswa SMP Raden Rahmat Wonokromo Surabaya.

\section{METODE PELAKSANAAN}

Penelitian ini menggunakan desain kualitatif lapangan. Penelitian kualitatif merupakan penelitian yang fokus untuk memahami fenomena tentang apa yang dialami oleh subyek penelitian seperti tindakan, persepsi, motifaperilaku, motivasi, dan lain-lain, secara holistik dan dengan cara deskripsi dalam bentuk katakata dan bahasa, pada suatu konteks khusus yang alamiyah dan dengan memanfaatkan berbagai metode alamiah.( Lexy J. Moleong, 2001)

Penulis mempelajari peristiwa atau fenomena yang terjadi di lapangan kemudian dianalisis menggunakan uraian deskriptif berupa kata-kata tertulis bukan dalam bentuk angka. (Nana Syaodih Sukmadinata, 2010)
Penelitian ini fenomena yang dianalisis adalah pemahaman siswi SMP Raden Rahmat kelas VIII pada pembelajaran materi haid dan Istikhadhah.

\section{HASIL DAN PEMBAHASAN}

Dari hasil penelitian yang sudah dilakukan ada beberapa soal yang dirasa masih membingungkan siswi yaitu soal tentang macam-macam warna darah haid, siswi banyak yang menjawab macammacam warna darah haid adalah hitam, merah, jambon, kuning dan keruh, padahal jambon bukanlah warna darah haid. Adapun macam-macam warna darah haid yaitu merah kehitaman, merah, kuning, coklat dan keruh.

Berkaitan dengan tata cara ibadah bagi perempuan yang sedang istihadhah, mereka kurang memperhatikan waktu wudhu ketika akan melaksanakan shalat. Siswi tidak mengetahui waktu berwudhu bagi perempuan yang sedang istihadhah adalah setelah masuk waktu shalat dan sesegera mungkin harus melaksanakan shalat. Jika wudhunya belum memasuki waktu shalat maka shalat yang dikerjakanpun tidak sah.

Pemahaman materi haid dan istihadhah yang memadai bagi setiap siswi akan mempermudah mereka dalam menghadapi permasalahan-permasalahan seputar haid dan istihadhah dalam kehidupan sehari-hari mereka nantinya. Mengingat perempuan juga nantinya akan menjadi seorang ibu yang pastinya akan memberikan informasi kepada anak-anaknya berkenaan dengan materi tersebut. Jika informasi yang di dapat sekarang salah takutnya kesalahan tersebut akan meluas kepada anakanaknya. Namun jika mereka sudah memahami secara mendalam maka akan memberikan efek positif kepada penerusnya.

Faktor-Faktor yang Mempengaruhi Pemahaman Siswi pada Materi Haid dan 
Istihadhah Kelas VIII di SMP Raden Rahmat Surabaya

a. Kehadiran siswanya, meskipun siswanya bukan hanya perempuan saja akan tetapi juga laki-laki, tetapi tidak menghalangi proses pembelajaran.

b. Sebagian besar siswanya sudah pernah mempelajari materi haid dan istihadhah di Madrasah Diniyyah, ataupun mereka sudah mendapatkan materi tersebut dari orangtuanya meskipun hanya dasardasarnya saja

c. Karena gurunya mempunyai pengalaman riil terkait masalah haid dan istihadhah. Jadi informasi yang diberikan kepada siswa lebih lengkap dan jelas.

\section{KESIMPULAN}

Hasil analisis dalam penelitian tentang "pemahaman materi haid dan istihadhah pada siswi kelas VIII SMP Raden Rahmat Surabaya", menerangkan bahwa tingkat pemahaman siswa pada materi haid dan istikhadoh baik. Hal ini dapat dilihat dari hasil wawancara dan juga hasil tes tertulis yang telah diberikan kepada siswa, dari hasil wawancara yang diberikan kepada beberapa siswi di SMP Raden Rahmat Wonokromo Surabaya, mereka sangat antusias memperhatikan pembelajaran tentang materi darah haid dan darah istihadhah karena dengan belajar materi darah haid dan darah istihadhah mereka menjadi faham tentang sesuatu yang berkaitan dengan masalah darah wanita yang sebelumnya mereka belum mengetahuinya. Walaupun ada sebagian materi yang belum semua difahami oleh siswa seperti berbagai macam darah haid wanita, wudhu bagi perempuan istihadhah, dan bagaimana cara mengqadha shalat bagi perempuan haid.

Hasil dari rincian penjelasan diatas dapat disimpulkan bahwa tingkat pemahaman materi haid dan istihadhah siswi kelas VIII SMP Raden Rahmat Karangrejo Wonokromo Surabaya baik, dapat diamati dari hasil wawancara dan hasil tes tertulis mereka walaupun ada sebagian siswi yang belum memahami materi tersebut dengan baik dan masih ada sebagaian materi yang mana siswa merasa sulit untuk memahaminya.

\section{SARAN}

Bagi SMP Raden Rahmat Karangrejo Wonokromo Surabaya hendaknya sekolah SMP Raden Rahmat memberikan materi haid dan istihadhah ini tidak hanya diajarkan pada saat kelas VIII saja dan materi ini hanya diberikan satu semester aja, karena sangat penting mempelajari materi haid dan istihadhah bagi setiap siswi supaya mereka benar-benar memahami maka hendaknya ditambahkan jam khusus.

\section{REFERENSI}

Ad-Dimasyqi, Syaikh al-'Allamah Muhammad bin 'Abdurrahman, Fiqih Empat Mazhab, 2013, Bandung: Hasyimi

Al-'Adawy, Syaikh Musthafa, 2008, Ensiklopedi Fiqih Wanita Jilid I, Jakarta: Qisthi Press

Al Asqolani, Ibnu Hajjar, Buluhulhumaram, Imaratullah, t.t AlHafidz, Ahsln W., Fikih Kesehatan, 2007, Jakarta: Amzah

Ali, Mohammad, Memahami Riset Perilaku dan Sosial, Bandung: Cendekia Utama

Arikunto, Suharsimi, 2006, Prosedur

Penelitian Suatu Pendekatan

Praktik,Jakarta: PT. Rineka Cipta

Arifin, Zainal, 2012, Evaluasi

Pembelajaran, Bandung: PT. Remaja

Rosdakarya

Fuad, Muhammad, 2007, Fiqih Wanita

Lengkap (mencakup isi hukum wanita dalam kehidupan sehari-hari), Jombang: Lintas Media

Hajjaj, Imam Abi Husaini Muslim Ibnu, Shahih Muslim, Dar Al-Fikr, t.t 
Hawwas, Abdul Aziz Muhammad Azzam

dan Abdul Wahhab Sayyed, 2009,

Fiqih Ibadah (Thaharah, Shalat, Zakat,

Puasa, dan Haji), Jakarta:

AMZAH,

Sudjanan, Nana, 2008, Penilaian Hasil

Proses Belajar Mengajar, Bandung:

PT. Remaja Rosdakarya

Sudjiono, Anas, 1996, Pengantar Evaluasi

Pendidikan, Jakarta: Raja Grafindo

Persada

Sugiyono, 2007, Metode Penelitiann

Pendidikan: Pendekatan Kuantitatif,

Kualitatif, dan $R \& D$, Bandung:

Alfabeta 

